\title{
The Role of Insulin and Glucagon in the Regulation of Basal Glucose Production in the Postabsorptive Dog
}

\author{
A. D. Cherrington, J. L. Chiasson, J. E. Liljenquist, A. S. Jennings, \\ U. KELLER, and W. W. LACY \\ From the Departments of Physiology and Medicine, Vanderbilt University Medical School, \\ Nashville, Tennessee 37232
}

\begin{abstract}
A B S TRACT The aim of the present experiments was to determine the role of insulin and glucagon in the regulation of basal glucose production in dogs fasted overnight. A deficiency of either or both pancreatic hormones was achieved by infusing somatostatin $(1 \mu \mathrm{g} / \mathrm{kg}$ per min), a potent inhibitor of both insulin and glucagon secretion, alone or in combination with intraportal replacement infusions of either pancreatic hormone. Infusion of somatostatin alone caused the arterial levels of insulin and glucagon to drop rapidly by $72 \pm 6$ and $81 \pm 8 \%$, respectively. Intraportal infusion of insulin and glucagon at rates of $400 \mu \mathrm{U} / \mathrm{kg}$ per min and $1 \mathrm{ng} / \mathrm{kg}$ per min, respectively, resulted in the maintenance of the basal levels of each hormone. Glucose production was measured using tracer (primed constant infusion of $\left[3-{ }^{3} \mathrm{H}\right]$ glucose) and arteriovenous difference techniques.
\end{abstract}

Isolated glucagon deficiency resulted in a $35 \pm 5 \%$ $(P<0.05)$ rapid and sustained decrease in glucose production which was abolished upon restoration of the plasma glucagon level. Isolated insulin deficiency resulted in a $52 \pm 16 \%(P<0.01)$ increase in the rate of glucose production which was abolished when the insulin level was restored. Somatostatin had no effect on glucose production when the changes in the pancreatic hormone levels which it normally induces were prevented by simultaneous intraportal infusion of both insulin and glucagon.

In conclusion, in the anesthetized dog fasted over-

This work was presented in part at the Annual Meeting of the Federation of American Societies for Experimental Biology in Atlantic City, N. J., April, 1975.

Dr. Cherrington was a Fellow of the Medical Research Council of Canada. Dr. Liljenquist is an Investigator of the Howard Hughes Medical Institute. Dr. Chiasson was a recipient of an Award for Reearch and Development from the American Diabetes Association. Dr. Keller was supported by the Swiss National Research Fund.

Received for publication 30 March 1976 and in revised form 23 August 1976. night: (a) basal glucagon is responsible for at least one-third of basal glucose production, $(b)$ basal insulin prevents the increased glucose production which would result from the unrestrained action of glucagon, and $(c)$ somatostatin has no acute effects on glucose turnover other than those it induces through perturbation of pancreatic hormone secretion. This study indicates that the opposing actions of the two pancreatic hormones are important in the regulation of basal glucose production in the postabsorptive state.

\section{INTRODUCTION}

The ability of glucagon to increase hepatic glucose production has been well documented both in vivo (1-3) and in vitro $(4,5)$. Similarly, the inhibitory action of insulin on glucose output has been clearly established (6-10). Recent studies with isolated rat liver cells (11) and perfused rat livers (12-14) have suggested, in fact, that the two hormones interact to regulate hepatic glucose metabolism. This concept has proved more difficult to establish in vivo because of the potent glucoregulatory feedback loops which exist in the whole animal.

Assessment of the role of basal amounts of insulin and glucagon in the regulation of basal glucose production has proved even more difficult, not only because of the counterregulatory changes which ensue after perturbation of the level of either hormone, but also because it has been difficult to totally inhibit glucagon secretion. Glucagon, immunologically identical to pancreatic glucagon, has now been shown to be present in the gastrointestinal tract of various species $(15,16)$, most notably the dog (17). For this reason, even pancreatectomy has often been ineffective in creating glucagon deficiency (18-20).

Somatostatin, a hypothalamic growth hormone release inhibiting factor, has been shown to inhibit the secretion of insulin and glucagon both in vivo 
(21-24) and in vitro $(25,26)$. This peptide has been shown not only to inhibit the secretion of glucagon by the pancreas but also the release of glucagon from the gut (27). Its mechanism of action remains unclear but may involve modification of calcium flux $(25,28,29)$ and or cyclic nucleotide levels $(30,31)$. Regardless of the manner in which it works, somatostatin provides a pharmacologic means by which one can simultaneously inhibit the secretion of both pancreatic hormones and thus break the glucoregulatory feedback loops which exist in vivo without surgical stress or the chronic metabolic alterations which result from pancreatectomy.

The aim of the present study was to determine the role of basal insulin and glucagon in the regulation of glucose production in the postabsorptive dog. Glucose production was measured by both tracer and arteriovenous difference techniques. Somatostatin was infused to inhibit the endogenous secretion of insulin and glucagon and then either or both of the hormones was selectively replaced. Replacement was achieved by intraportal infusion of the required hormone at a rate equivalent to its basal secretion rate. In this way a deficiency of either or both hormones was produced and the role of insulin and glucagon in the regulation of basal glucose output was defined.

\section{METHODS}

Animals and surgical procedures. Experiments were carried out on 28 mongrel dogs $(18-25 \mathrm{~kg}$ ) unspecified as to sex, which had been fed a high protein diet (Wayne Dog Chow, Wayne Lab-Blox, Allied Mills, Inc., Chicago, Ill.) for $3 \mathrm{wk}$. $1 \mathrm{wk}$ before each experiment, two silastic catheters were inserted into the splenic vein under general anesthesia (sodium pentobarbital, $25 \mathrm{mg} / \mathrm{kg}$ i.v.). The tip of one catheter was located approximately $2 \mathrm{~cm}$ from the entry of the portal vein into the liver and the tip of the other was located at the junction of the splenic and portal veins. During the experiment, the catheter proximal to the liver was used for blood withdrawal, while the catheter in the splenic vein was used for intraportal hormone infusion.

$1 \mathrm{wk}$ was allowed for recovery after the surgery. Blood was withdrawn 2 days before each experiment to determine the animals leukocyte count and hematocrit. Only dogs meeting the following criteria were used for an experiment: they had to have (a) normal body temperature, (b) leukocyte count below $16,000 \mathrm{~mm}^{3},(c)$ hematocrit above $38 \%$, (d) good appetite (consuming $>$ two-thirds of daily ration), and $(e)$ normal stools.

Each dog was studied under sodium pentobarbital anesthesia $(25-35 \mathrm{mg} / \mathrm{kg}$ i.v. ) after an overnight fast (14-16 h). An endotracheal tube was inserted immediately after induction of the anesthesia and the animal was ventilated at a rate of $12-14$ respirations per min with a tidal volume of $400 \mathrm{ml}$. Angiocaths (14 gauge) were inserted percutaneously into the left jugular, cephalic, and saphenous vein to allow infusion of cardiogreen, $\left[3-{ }^{3} \mathrm{H}\right]$ glucose, and somatostatin, respectively. A small cut-down was performed over the left inguinal area to isolate the femoral artery which was also cannulated with a 14-gauge angiocath. The right jugular vein was exposed by a small cut down and a radio-opaque catheter was guided through it into the major left hepatic vein where its tip was located $3-4 \mathrm{~cm}$ from the wedge position. Continuous infusion of heparin-saline $(0.02 \mathrm{U} / \mathrm{ml} ; 0.5 \mathrm{ml} / \mathrm{min})$ maintained the patency of the hepatic vein catheter. The femoral arterv and the hepatic vein catheters, as well as the previously inserted portal vein catheter, were used for blood sampling. At the end of each experiment the patency and location of all catheter tips was verified.

Upon completion of the cannulations the dog was draped with a heating blanket to maintain a constant body temperature. Blood pressure, pulse rate, rectal temperature, $\mathrm{PO}_{2}$, $\mathrm{PCO}_{2}, \mathrm{pH}$, and hematocrit were monitored at 30-min intervals throughout the study to confirm the stability of each preparation and to ensure adequate ventilation.

Experimental design. Each experiment consisted of a 90-min tracer and dye equilibration period (0-90 min) followed by a 40 -min control period $(90-130 \mathrm{~min})$, a $70-\mathrm{min}$ period of hormone perturbation (130-200 $\mathrm{min}$ ), and a $30-\mathrm{min}$ rebound period $(200-230 \mathrm{~min})$. The primed constant infusions of $\left[3-{ }^{3} \mathrm{H}\right]$ glucose $(0.76 \mu \mathrm{Ci} / \mathrm{min})$ and the infusion of cardiogreen $\left(0.075 \mathrm{mg} / \mathrm{M}^{2}\right.$ per min) were started at $t=0$ and continued throughout the study. The priming dose of [3- $\left.{ }^{3} \mathrm{H}\right]$ glucose equaled the amount infused in $140 \mathrm{~min}$.

Somatostatin $(1 \mu \mathrm{g} / \mathrm{kg}$ per min) was infused from $130-200$ min alone or in combination with intraportal glucagon ( $1 \mathrm{ng} / \mathrm{kg}$ per min) and(or) insulin (400 $\mu \mathrm{U} / \mathrm{kg}$ per min). Insulin or glucagon replacement was considered adequate when the resulting arterial hormone concentration did not differ by more than $20 \%$ (approximately $\pm 3 \mu \mathrm{U} / \mathrm{ml}$ for insulin and $\pm 20 \mathrm{pg} / \mathrm{ml}$ for glucagon from its control period mean value. 16 of 20 dogs in which replacement of one or both pancreatic hormones was attempted met the above criteria, the results from experiments conducted on the four dogs in which replacement was inadequate were not included. In these animals the usual replacement doses were inappropriate and the resulting hormone levels did not match those of the control period.

Five different types of experiments were performed: (a) saline infusion, to assess the stability of the animals; (b) somatostatin infusion, to study the effects of combined insulin and glucagon deficiency; (c) somatostatin plus intraportal insulin replacement, to assess the effects of glucagon deficiency; (d) somatostatin plus intraportal glucagon replacement, to study the effects of insulin deficiency; and (e) somatostatin plus intraportal insulin and glucagon replacement, to examine the influence of the nonpancreatic effects of somatostatin on the observed changes. Samples were drawn every $10 \mathrm{~min}$ throughout each experiment.

Processing of blood sample. The collection and immediate processing of blood samples have been described previously (32). Equivalent aliquots of the infusate tracer solution were added to $5 \mathrm{ml}$ of the dog's plasma (drawn immediately before the experiment) and to $5 \mathrm{ml}$ of distilled water (saturated with benzoic acid and containing $100 \mathrm{mg} / 100 \mathrm{ml}$ glucose) to monitor the recovery of glucose. Two aliquots of each solution were then run with the samples and the counts obtained were compared to those expected. Recovery varied from $92-98 \%$. Glucose was isolated with the aid of cationic and anionic exchange resins. Radioactive water was removed from the glucose samples by overnight evaporation in a vacuum oven at $60^{\circ} \mathrm{C}$. Such treatment did not result in a loss of the $\left[3-{ }^{3} \mathrm{H}\right]$ glucose. The radioactivity of plasma samples was determined with liquid scintillation counting procedures. The plasma concentrations of glucose were determined by the glucose oxidase method with a Beckman glucose analyzer (Beckman Instruments, Inc., Fullerton, Calif.) and the whole blood glucose concentrations were monitored within $4 \mathrm{~min}$ with the Hoffman ferricyanide reaction in a Technicon 
AutoAnalyzer (Technicon Instruments Corp., Tarrytown, N. Y.). Immunoreactive glucagon (IRG) ${ }^{1}$ was assayed using $30 \mathrm{~K}$ antiserum of Unger in plasma samples to which $200 \mathrm{U} / \mathrm{ml}$ of Trasylol had been added (33). Immunoreactive insulin (IRI) was measured by the Sephadex bound-antibody procedure (34). Plasma concentrations of indocyanine green were determined in a Beckman spectrophotometer (Beckman Instruments, Inc.) at $815 \mathrm{~nm}$ according to Leevy et al. (35).

Materials. $\left[3^{-3} \mathrm{H}\right]$ Glucose (New England Nuclear, Boston, Mass.) was used as the glucose tracer $(500 \mu \mathrm{Ci} / 0.015 \mathrm{mg})$. Insulin and glucagon were purchased from Eli Lilly and Company, Indianapolis, Ind. and indocyanine green was purchased from Hynson, Westcott \& Dunning, Inc., Baltimore, Md. Phadebas Insulin Radioimmunoassay Kit was purchased from Pharmacia Fine Chemicals, Inc., Piscataway, N. J. and Trasylol was obtained from FBA Pharmaceuticals, Inc., New York. Glucagon 30K antiserum was bought from Dr. Roger Unger, Dallas, Tex., and the standard glucagon and ${ }^{125} \mathrm{I}$-glucagon was obtained from Novo Research Institute, Copenhagen, Denmark. All solutions were prepared with normal saline and contained $1 \%$ bovine albumin $/ 100 \mathrm{ml}$ saline. The infusate tracer solution also contained added glucose such that its final concentration was $1 \mathrm{mg} / \mathrm{ml}$. Linear somatostatin was obtained from Bachem, Inc., Marina Del Rey, Calif.

Tracer methods and calculations. The rates of endogenous glucose production ("rate of appearance") and utilization or uptake ("rate of disappearance") were determined by the method of primed tracer infusion. Calculation of the rates was carried out according to the method of Wall et al. (36) as simplified by De Bodo et al. (1). This method is based on a single compartment analysis of glucose kinetics in which it is assumed that rapid changes in the specific activity and concentration of glucose do not occur uniformly within the entire glucose pool. To compensate for this nonuniform mixing, it was originally suggested that the nonsteady-state term of the equation be multiplied by a correction factor (pool fraction) of 0.5. Recently Cowan and Hetenyi estimated experimentally that the pool fraction for normal dogs was approximately 0.65 (37). This pool fraction was, therefore, used in the present calculations. A sliding-fit technique that employed three consecutive values of glucose concentration and specific activity was also used in the calculations as described previously (38). Calculation of nonsteady-state turnover rates with the pool fraction method of DeBodo et al. and Wall et al. $(1,36)$ has now been validated for both inulin (39) and glucose (40) and has been shown to yield accurate measurements over a wide range of deviations from steady state $(39,40)$.

Glucose production was also calculated by the arteriovenous $(\mathrm{A}-\mathrm{V})$ difference technique. This method involves calculation of hepatic blood flow by using cardiogreen as described previously $(32,35)$ and determination of the glucose difference across the liver. The latter was accomplished knowing the portal, arterial, and hepatic vein whole blood glucose concentrations and assuming that $70 \%$ of the hepatic blood flow is derived from the portal vein (41). The product of blood flow and the A-V difference represents net hepatic glucose production. Somatostatin did not affect blood flow in these experiments. Specific data regarding this point will be published elsewhere. ${ }^{2}$ It should be noted that the tracer method would yield accurate rates of glucose production even if blood flow to the liver were to change.

\footnotetext{
${ }^{1}$ Abbreviations used in this paper: A-V, arteriovenous; IRG, immunoreactive glucagon; IRI, immunoreactive insulin.

${ }^{2}$ Jennings, A. S., et al. Manuscript in preparation.
}

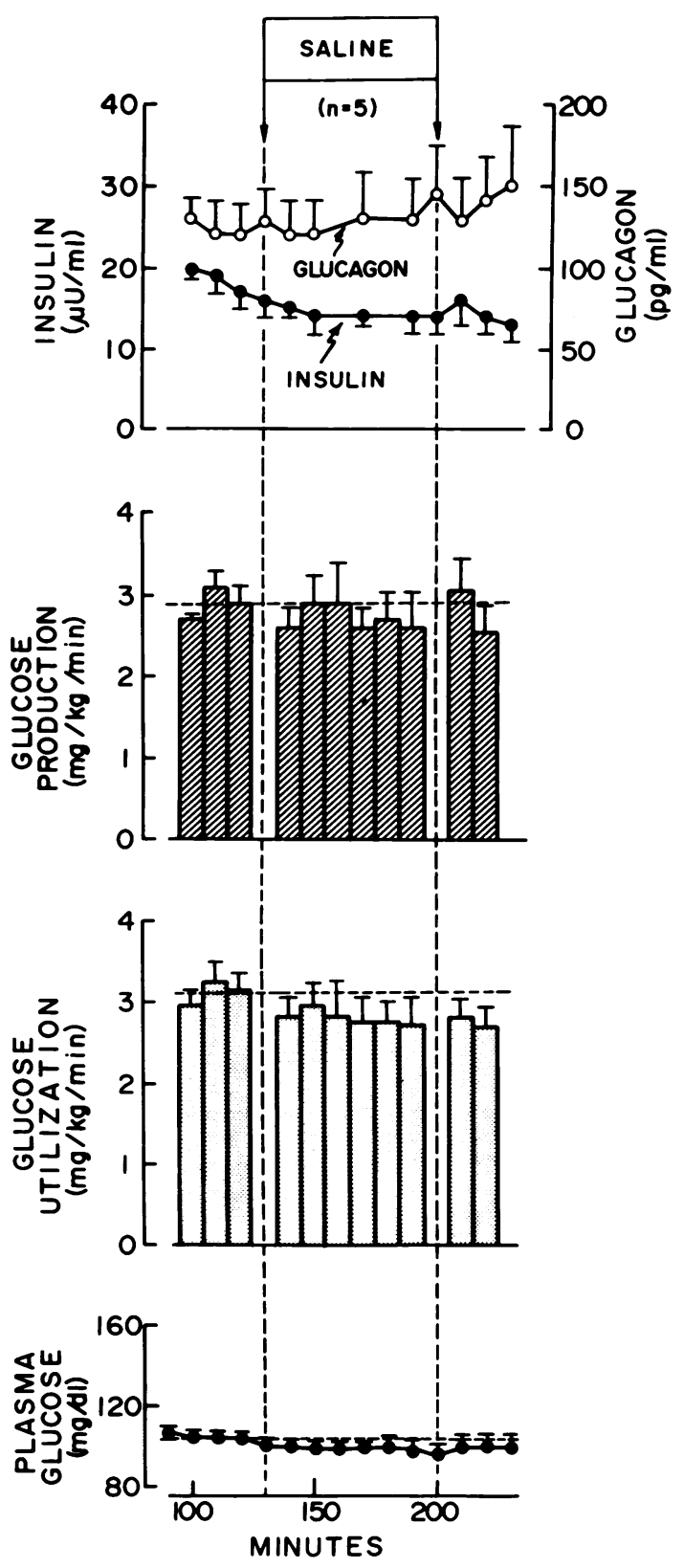

FIGURE 1 The effects of saline infusion on arterial plasma IRI and IRG levels and on the production, utilization, and concentration of plasma glucose in normal dogs. Values are means \pm SEM. Glucose turnover was measured isotopically.

Statistical analyses were carried out with the Student $t$ test and the paired $t$ test (42).

\section{RESULTS}

Saline infusion. Fig. 1 illustrates that the infusion of saline did not effect the plasma concentrations of insulin, glucagon, or glucose or the mean rates of 


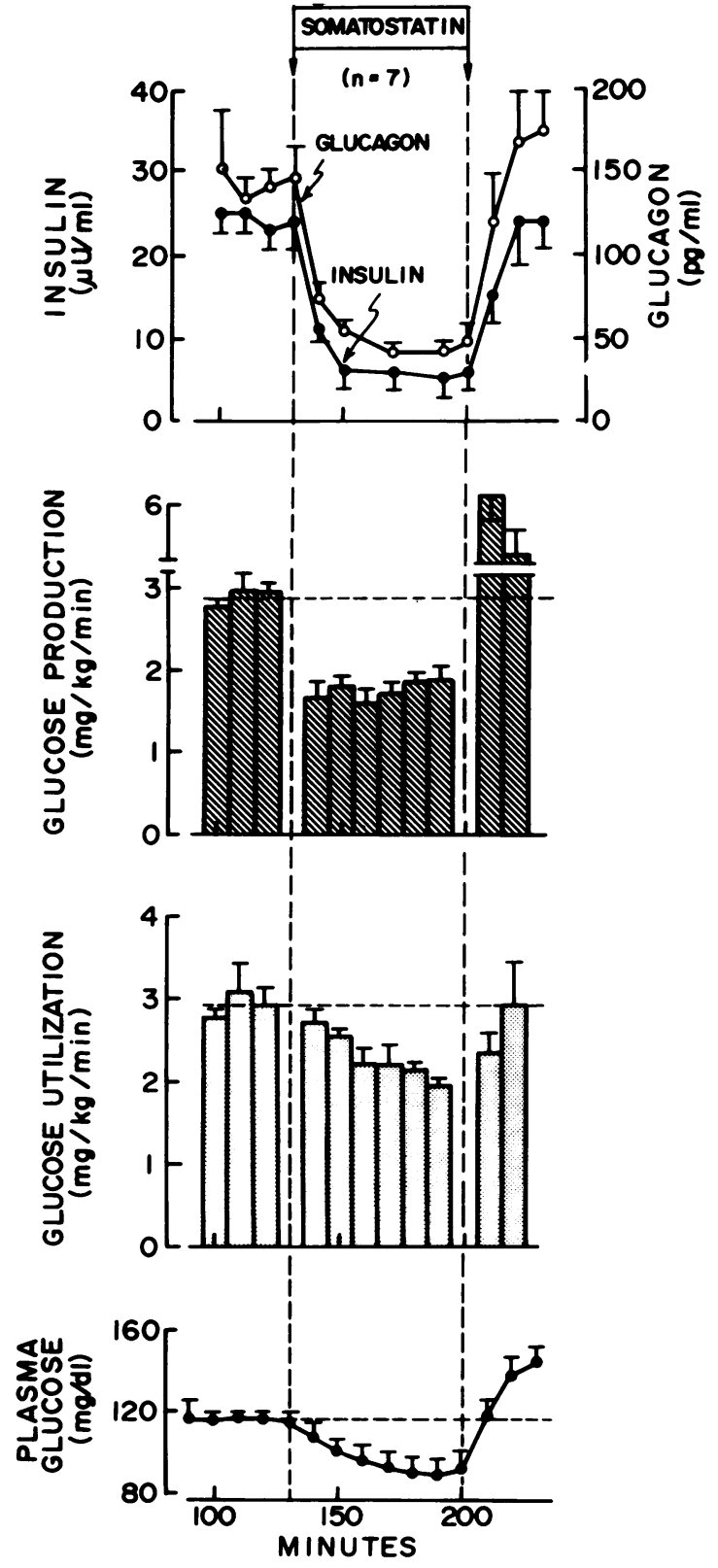

FIGURE 2 The effects of somatostatin infusion $(1 \mu \mathrm{g} / \mathrm{kg}$ per min) on arterial plasma IRI and IRG levels and on the production, utilization, and concentration of plasma glucose in normal dogs. Values are means $\pm S E M$. Glucose turnover was measured isotopically.

glucose production or utilization. All measured parameters were stable throughout the experiment with the exception of insulin which declined slightly during the control period.

Somatostatin infusion. Fig. 2 illustrates the mean data from seven experiments in which somatostatin produced a concurrent deficiency of both pancreatic hormones. Arterial glucagon dropped by $72 \%$ to a mean level of $38 \mathrm{pg} / \mathrm{ml}$, while insulin declined by $81 \%$ to a mean concentration of less than $5 \mu \mathrm{U} / \mathrm{ml}$. Portal vein IRI and IRG levels declined by 88 and $81 \%$, respectively, reaching levels similar to those found in arterial plasma (Table I). These hormonal changes were associated with a significant $(P<0.01)$ and sustained decrease (average drop of $40 \pm 5 \%$ ) in the rate of glucose production (Table II, Fig. 2). Since the rate of glucose utilization exceeded the rate of glucose production after initiation of the somatostatin infusion, the plasma glucose level began to fall. Eventually, however, the two rates became synchronous and the plasma glucose level plateaued. Glucose utilization fell as a result of both insulin lack and the lower glucose level (i.e. mass effect). Fig. 2 also demonstrates that the hormone concentrations were rapidly reestablished when the somatostatin infusion was terminated. Recovery of glucagon occurred more rapidly than that of insulin and these changes were associated with a tripling of the rate of glucose production and a rapid rebound in the glucose level.

Glucagon deficiency. Fig. 3 illustrates the consequences of isolated glucagon deficiency which was produced when somatostatin was given concurrently with an intraportal infusion of insulin. Insulin replacement prevented the somatostatin-induced drop in the IRI concentration and maintained the arterial insulin level at $13 \pm 1 \mu \mathrm{U} / \mathrm{ml}$. Maintenance of the insulin level is also reflected in the portal vein IRI concentrations (39 $\pm 6 \mu \mathrm{U} / \mathrm{ml}$; Table I). The plasma glucagon concentration, on the other hand, declined rapidly, reaching a mean level of $31 \mathrm{pg} / \mathrm{ml}$ in arterial plasma (Fig. 3). As in the case of a deficiency of both pancreatic hormones, glucose production fell in a rapid and sustained manner (average drop of $35 \pm 5 \%$; $P<0.01$; Table III; Fig. 3). The plasma glucose concentration and the rate of glucose utilization also fell, as in the previous protocol. In this case, however, the fall in glucose utilization was slightly less and was entirely attributable to the decreasing glucose concentration. Upon cessation of the somatostatin and insulin infusions the glucagon concentration rebounded, while the insulin level remained relatively unchanged. The sudden increase in the glucagon level was associated with a normalization of the rate of glucose production and an increase in the plasma glucose concentration.

Insulin deficiency. Fig. 4 illustrates the mean data from experiments in which a specific insulin deficiency was created by giving somatostatin simultaneously with an intraportal glucagon infusion. Glucagon replacement prevented the somatostatin-induced drop in the IRG concentration and resulted in the maintenance of the arterial glucagon level at $113 \pm 22 \mathrm{pg} / \mathrm{ml}$. Portal IRG levels also remained relatively unchanged $(208 \pm 16 \mathrm{pg} / \mathrm{ml}$; Table I). The arterial insulin concentration, on the other hand, fell rapidly reaching a 
TABLE I

Portal Vein Concentrations of IRI and IRG in Dogs Given Somatostatin Alone or in Combination with Intraportal Insulin or Glucagon

\begin{tabular}{|c|c|c|c|c|c|c|c|c|c|c|c|}
\hline \multirow[b]{2}{*}{ Time, $\min \ldots \ldots$} & \multicolumn{3}{|c|}{ Control period } & \multicolumn{5}{|c|}{ Infusion period } & \multicolumn{3}{|c|}{ Recovery period } \\
\hline & 60 & 70 & 80 & 90 & 100 & 120 & 140 & 150 & 160 & 170 & 180 \\
\hline \multicolumn{12}{|l|}{ Insulin, $\mu U / m l$} \\
\hline Somatostatin & 53 & 50 & 51 & 10 & 8 & 6 & 6 & 6 & 39 & 57 & 51 \\
\hline $\operatorname{SEM}(n=7)$ & 7 & 7 & 8 & 2 & 2 & 1 & 1 & 1 & 10 & 11 & 5 \\
\hline Somatostatin + insulin replacement & 49 & 49 & 48 & 40 & 38 & 40 & 38 & 38 & 29 & 38 & 36 \\
\hline $\operatorname{SEM}(n=7)^{*}$ & 9 & 13 & 13 & 8 & 6 & 9 & 5 & 6 & 3 & 4 & 9 \\
\hline \multicolumn{12}{|l|}{ Glucagon, $p g / m l$} \\
\hline Somatostatin & 187 & 186 & 183 & 65 & 48 & 42 & 38 & 43 & 139 & 230 & 208 \\
\hline $\operatorname{SEM}(n=7)$ & 26 & 15 & 21 & 6 & 7 & 5 & 9 & 10 & 25 & 70 & 39 \\
\hline Somatostatin + glucagon replacement & 227 & 223 & 234 & 183 & 208 & 213 & 211 & 192 & 172 & 206 & 194 \\
\hline $\operatorname{SEM}(n=6)^{*}$ & 50 & 90 & 51 & 16 & 26 & 24 & 40 & 33 & 12 & 23 & 23 \\
\hline
\end{tabular}

* Since portal samples were not obtained from all dogs, the values from each experiment in which the designated hormone was replaced were meaned, whether or not the other hormone was replaced.

level of less than $5 \mu \mathrm{U} / \mathrm{ml}$ (Fig. 4). The resulting deficiency of insulin was associated with a significant $(P<0.01)$ increase in the rate of glucose production (average rise of $52 \pm 16 \%$; Table III; Fig. 4). As a result of glucose overproduction hyperglycemia progressively developed. Overall glucose utilization remained unchanged probably as the result of the offsetting effects of hyperglycemia and insulin lack. Upon cessation of the somatostatin and glucagon infusions the plasma insulin concentration returned to normal while the plasma glucagon level remained unchanged. The resulting normalization of the hormone levels was associated with a rapid cessation of the overproduction of glucose and a fall in the glucose level.

Nonpancreatic effects of somatostatin. Fig. 5 illustrates the mean data from six experiments in which somatostatin was given simultaneously with intraportal infusion of both pancreatic hormones. The purpose of these experiments was to assess the role that the nonpancreatic effects of somatostatin may have had

TABLE II

The Rates of Glucose Production during Saline or Somatostatin Infusion into Normal Dogs*

\begin{tabular}{|c|c|c|c|c|c|c|c|c|c|c|c|}
\hline \multirow[b]{3}{*}{ Dog } & \multicolumn{11}{|c|}{ Period, $\min$} \\
\hline & \multicolumn{3}{|c|}{ Control } & \multicolumn{6}{|c|}{ Infusion } & \multicolumn{2}{|c|}{ Recovery } \\
\hline & 95 & 5 & 5.125 & $135 \quad 1$ & & 1 & & & 195 & $205 \quad 215$ & 225 \\
\hline \multicolumn{12}{|l|}{ Saline } \\
\hline 1 & 2.47 & 2.79 & 2.43 & 2.68 & 2.25 & 1.80 & 2.24 & 2.16 & 1.66 & 2.36 & 2.06 \\
\hline 2 & 2.87 & 3.40 & 3.58 & 3.48 & 4.08 & 4.60 & 3.42 & 3.90 & 4.14 & 4.49 & 3.86 \\
\hline 3 & 2.79 & 2.62 & 2.66 & 1.91 & 2.26 & 2.07 & 2.18 & 2.31 & 2.57 & 2.52 & 1.85 \\
\hline 4 & 2.57 & 2.86 & 2.47 & 2.45 & 3.02 & 2.80 & 2.59 & 2.69 & 2.39 & 3.11 & 2.41 \\
\hline 5 & 2.78 & 3.94 & 3.18 & 2.48 & 2.82 & 2.99 & 2.76 & 2.19 & 2.13 & 2.79 & 2.41 \\
\hline \multicolumn{12}{|c|}{ Somatostatin } \\
\hline 6 & - & 4.06 & 3.40 & 1.12 & 1.91 & 2.38 & 1.87 & 1.67 & - & - & - \\
\hline 7 & - & 3.20 & 3.20 & 2.41 & 2.28 & 1.43 & 2.04 & 1.83 & 1.49 & 10.08 & 10.36 \\
\hline 8 & - & 2.32 & 2.64 & 1.39 & 2.00 & 1.08 & 1.09 & 2.19 & 1.86 & 4.57 & 4.49 \\
\hline 9 & 2.88 & 2.89 & 2.67 & 2.55 & 1.82 & 1.77 & 2.16 & 2.39 & 2.55 & 5.14 & 3.41 \\
\hline 10 & 2.71 & 3.25 & 3.31 & 1.20 & 1.38 & 1.31 & 1.24 & 1.43 & 1.54 & 4.47 & 4.05 \\
\hline 11 & 3.00 & 2.69 & 2.65 & 1.15 & 1.33 & 1.62 & 1.74 & 1.57 & 1.80 & 7.46 & 3.27 \\
\hline 12 & 2.40 & 2.32 & 2.70 & 1.74 & 1.79 & 1.67 & 1.79 & 1.85 & 1.97 & 4.98 & 4.63 \\
\hline
\end{tabular}

* Glucose production rates are expressed in milligrams per kilogram per minute; the somatostatin infusion rate was as 1 microgram per kilogram per minute. 


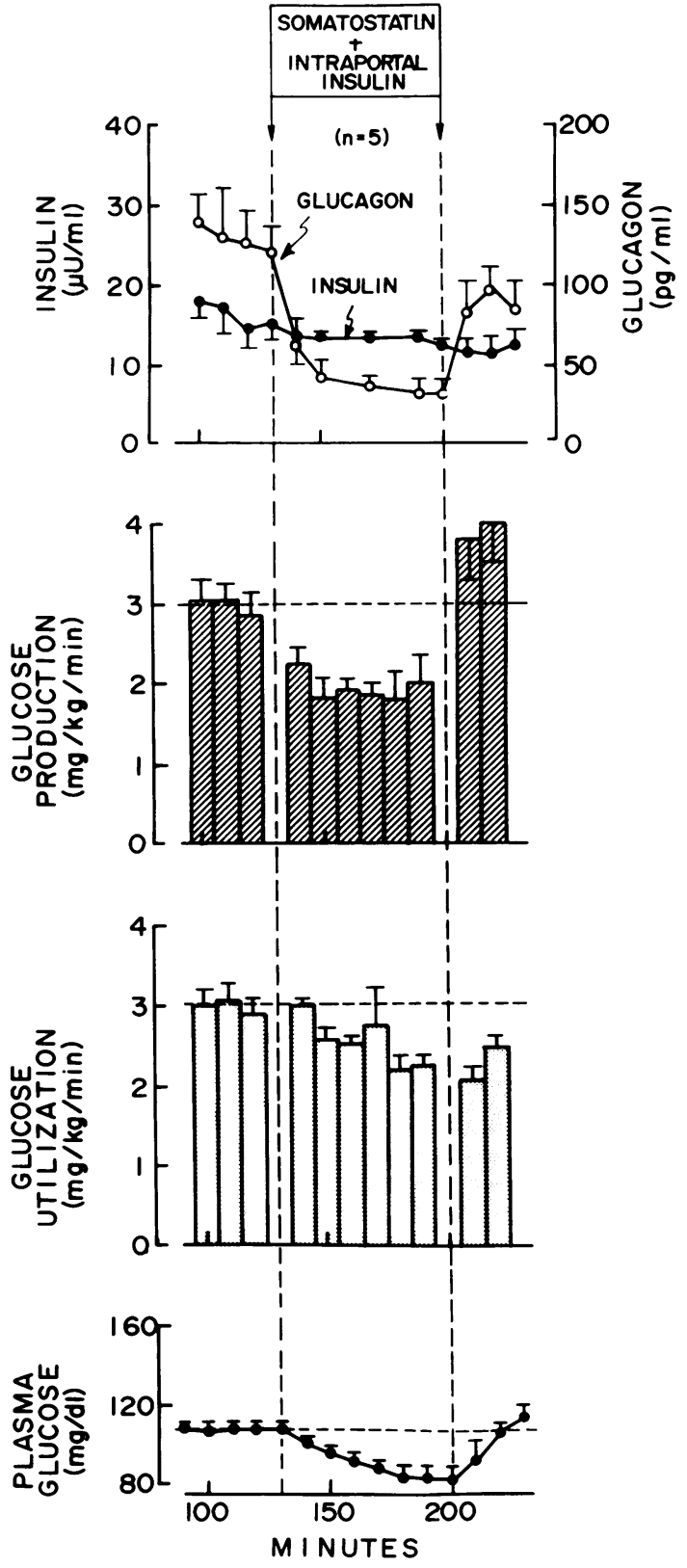

Figure 3 The effects of somatostatin infusion ( $1 \mu \mathrm{g} / \mathrm{kg}$ per min) combined with intraportal insulin replacement (400 $\mu \mathrm{U} / \mathrm{kg}$ per min) on arterial plasma IRI and IRG levels and on the production, utilization, and concentration of plasma glucose in normal dogs. Values are means \pm SEM. Glucose turnover was measured isotopically.

in the observed responses. The success of hormonal replacement is evident from the finding that the mean glucagon concentration measured in arterial plasma during the control period (average $111 \pm 5 \mathrm{pg} / \mathrm{ml}$ ) was similar to that observed during the glucagon infusion period (average $117 \pm 2 \mathrm{pg} / \mathrm{ml}$ ). In addition, the mean plasma insulin concentrations were similar during the

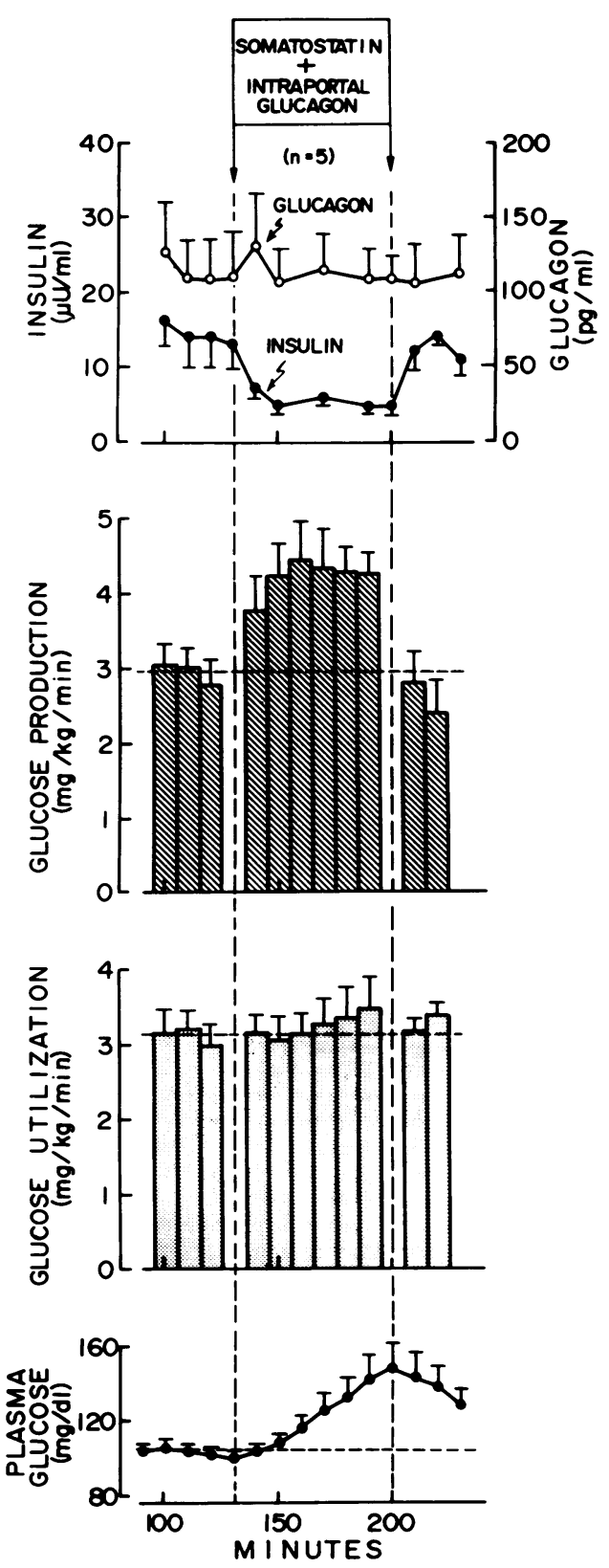

FIgURE 4 The effects of somatostatin infusion $(1 \mu \mathrm{g} / \mathrm{kg}$ per min) combined with intraportal glucagon replacement (1 $\mathrm{ng} / \mathrm{kg}$ per min) on arterial plasma IRI and IRG levels and on the production, utilization, and concentration of plasma glucose in normal dogs. Values are means $\pm S E M$. Glucose turnover was measured isotopically.

two periods ( $19 \pm 1$ and $17 \pm 2 \mu \mathrm{U} / \mathrm{ml}$, respectively). Hormonal replacement was also adequate when judged by portal vein values (Table I). When the effect of somatostatin on the pancreatic hormone levels was prevented, it had no significant effect on the rate of glucose production (Table III; Fig. 5). the intraportal replacement of both insulin and glucagon thus abolished 
TABLE III

The Rates of Glucose Production during Somatostatin and Either Intraportal Insulin or Intraportal Glucagon Infusion into Normal Dogs*

\begin{tabular}{|c|c|c|c|c|c|c|c|c|c|c|c|}
\hline \multirow[b]{3}{*}{ Dog } & \multicolumn{11}{|c|}{ Period, min } \\
\hline & \multicolumn{3}{|c|}{ Control } & \multicolumn{6}{|c|}{ Infusion } & \multicolumn{2}{|c|}{ Recovery } \\
\hline & $\underbrace{95} \sim^{1}$ & $\sqrt[5]{5}$ & $\underbrace{5} \overbrace{}^{125}$ & $135 \overbrace{}^{1}$ & 5 & 1 & 5 & $\underbrace{5}$ & $\underbrace{5} \overbrace{}^{195}$ & $205 \underbrace{2}$ & 5 \\
\hline \multicolumn{12}{|c|}{$\begin{array}{l}\text { Somatostatin } \\
+ \text { insulin }\end{array}$} \\
\hline 13 & 3.11 & 3.31 & 2.77 & 2.55 & 2.41 & 2.07 & 2.03 & 2.09 & 2.08 & 3.44 & 4.00 \\
\hline 14 & 3.70 & 3.10 & 2.58 & 2.67 & 2.14 & 2.24 & 2.16 & 2.85 & 3.09 & 4.20 & 2.63 \\
\hline 15 & 2.15 & 2.30 & 2.03 & 2.06 & 1.72 & 1.78 & 1.54 & 1.02 & 1.35 & 2.75 & 3.08 \\
\hline 16 & 3.22 & 3.31 & 3.36 & 2.28 & 1.28 & 1.87 & 1.75 & 1.37 & 2.10 & 3.24 & 5.95 \\
\hline 17 & 3.05 & 3.23 & 3.51 & 1.62 & 1.61 & 1.73 & 1.86 & 1.73 & 1.63 & 5.30 & 4.68 \\
\hline \multicolumn{12}{|c|}{$\begin{array}{l}\text { Somatostatin } \\
\text { + glucagon }\end{array}$} \\
\hline 18 & 2.00 & 2.08 & 1.74 & 2.00 & 2.99 & 4.42 & 4.34 & 3.81 & 3.88 & 3.52 & 1.98 \\
\hline 19 & 3.76 & 3.19 & 2.79 & 3.79 & 4.61 & 4.51 & 3.98 & 3.62 & 3.59 & 1.61 & 1.57 \\
\hline 20 & 3.11 & 2.57 & 2.30 & 3.93 & 3.47 & 2.63 & 2.72 & 3.54 & 3.64 & 2.73 & 3.23 \\
\hline 21 & 2.89 & 3.52 & 3.50 & 4.22 & 4.50 & 4.69 & 5.01 & 5.11 & 5.16 & 3.23 & 3.09 \\
\hline 22 & 3.37 & 3.57 & 3.55 & 5.00 & 5.60 & 5.92 & 5.77 & 5.51 & 5.20 & - & - \\
\hline \multicolumn{12}{|c|}{$\begin{array}{l}\text { Somatostatin } \\
\quad+\text { insulin } \\
\text { + glucagon }\end{array}$} \\
\hline 23 & 3.34 & 3.02 & 2.38 & 2.60 & 2.35 & 2.20 & 2.37 & 2.40 & 2.71 & 4.48 & 3.08 \\
\hline 24 & 1.82 & 2.18 & 2.03 & 1.50 & 1.46 & 1.54 & 1.67 & 1.80 & 1.46 & 4.75 & 5.62 \\
\hline 25 & 3.72 & 2.72 & 3.46 & 2.44 & 2.02 & 1.83 & 2.21 & 2.00 & 2.00 & 7.42 & 4.99 \\
\hline 26 & 2.53 & 2.89 & 3.27 & 3.22 & 3.57 & 3.09 & 2.89 & 3.27 & 3.93 & 2.60 & 3.14 \\
\hline 27 & 3.05 & 2.96 & 2.98 & 3.88 & 3.97 & 3.17 & 2.90 & 2.97 & 2.87 & 4.13 & 3.32 \\
\hline 28 & 3.82 & 2.65 & 3.41 & 2.50 & 3.37 & 4.12 & 3.62 & 3.89 & 3.39 & 3.99 & 4.17 \\
\hline
\end{tabular}

* Glucose production rates are expressed in milligrams per kilogram per minute; infusion rates are as follows: somatostatin, $1 \mu \mathrm{g} / \mathrm{kg}$ per min; intraportal insulin, $400 \mu \mathrm{U} / \mathrm{kg}$ per min; intraportal glucagon, $1 \mathrm{ng} / \mathrm{kg}$ per min.

the underproduction of glucose associated with glucagon deficiency and the overproduction of glucose associated with insulin deficiency. The rate of glucose utilization also remained unaltered during the infusion of somatostatin when the effect of the latter on the pancreatic hormone levels was prevented and consequently normoglycemia was maintained.

The small increase in glucose production which occurred after cessation of the hormone and somatostatin infusions was primarily the result of responses in two animals (nos. 24 and 25). In both cases the increased production of glucose was associated with an excessive rebound of glucagon which followed a slight decline in the glucose level during the hormone infusion period.

Role of the pancreatic hormones. In Fig. 6 the results of the present experiments are used to illustrate the approximate role each pancreatic hormone plays in the maintenance of hepatic glucose production in the anesthetized overnight fasted dog. One can conclude that at least one-third of basal glucose production was attributable to the presence of basal amounts of glucagon. Such basal levels of glucagon, however, were capable of stimulating about three times as much glucose production when a deficiency of insulin was apparent. The potent inhibitory effect of insulin on glucose production was thus clearly demonstrated. Since the insulin and glucagon levels apparently did not fall to zero in response to somatostatin, it should be pointed out that a total absence of either hormone might have resulted in a somewhat greater dependence of glucose production on basal glucagon.

Comparison of glucose production by isotopic and hepatic $A-V$ difference methods. Fig. 7 shows that the overproduction or underproduction of glucose associated with insulin or glucagon deficiency, respectively, were equally apparent whether a tracer or A-V technique was used to assess glucose production. Hepatic glucose output (determined by the A-V difference method) was slightly less than total glucose production (computed with isotopic data) in the control period of almost all experiments in which both tech- 


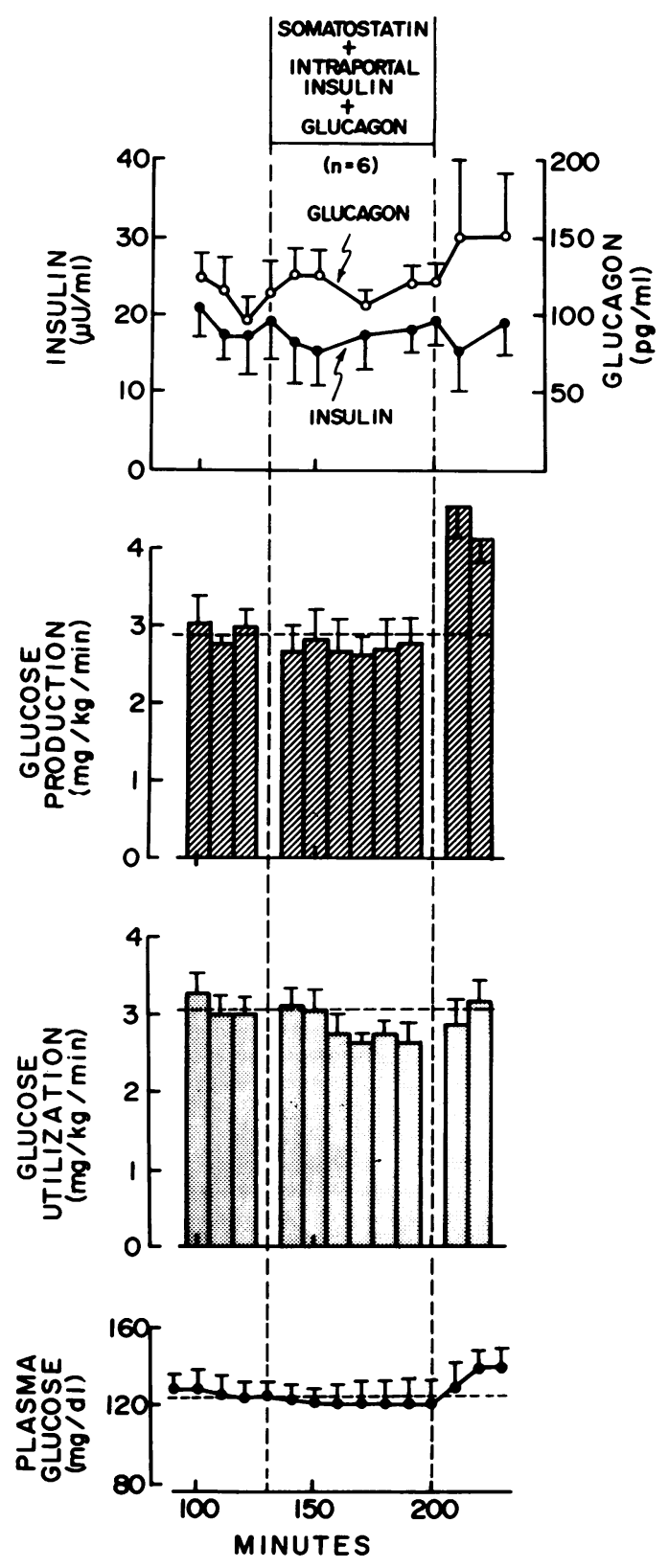

FIGURE 5 The effect of somatostatin ( $1 \mu \mathrm{g} / \mathrm{kg}$ per $\mathrm{min}$ ) combined with intraportal replacement of insulin and glucagon (400 $\mu \mathrm{U} / \mathrm{kg}$ per min and $1 \mathrm{ng} / \mathrm{kg}$ per min, respectively) on arterial plasma IRI and IRG levels and on the production, utilization, and concentration of plasma glucose in normal dogs. Values are means \pm SEM. Glucose turnover was measured isotopically.

niques were used. The percent of changes resulting from hormone perturbation, on the other hand, were somewhat larger when measured by the $\mathrm{A}-\mathrm{V}$ difference technique. Glucagon deficiency was associated with an average drop of $47 \%$ in hepatic glucose output and insulin deficiency resulted in an average increase of $71 \%$ in hepatic glucose production.
While the antagonistic effects of insulin and glucagon on glucose production have long been recognized, the quantitative aspects of their interaction after an overnight fast has not previously been defined. The present experiments demonstrate that glucagon plays a significant role in maintaining hepatic glucose production in the overnight fasted dog and that insulin acts as a potent antagonist to its action. The rate of glucose production in the postabsorptive state thus seems to reflect the balance between the stimulatory effect of glucagon and the inhibitory effect of insulin. It is the interplay between the two pancreatic hormones which is, at least in part, responsible for the regulation of glucose output by the liver.

In the majority of the present experiments, glucose production was measured by both a tracer technique and an A-V difference method. [3- $\left.{ }^{3} \mathrm{H}\right]$ Glucose was used as the tracer molecule to allow accurate assessment of the rate of glucose production $(43,44)$. Since the ${ }^{3} \mathrm{H}$ atom in position three of glucose is lost to body water and cannot recirculate $(43,45)$ its use eliminates the underestimation which might otherwise result from recycling of the label (2). The absence of recirculation in the present experiments was confirmed by the lack of either $\left[{ }^{3} \mathrm{H}\right]$ alanine or $\left[{ }^{3} \mathrm{H}\right]$ lactate in plasma even after four $\mathrm{h}$ of $\left[3^{-} \mathrm{H}\right]$ glucose infusion. The overestimate of glucose production which can arise due to loss of label as the result of futile cycling (44) is also negligible when $\left[3-{ }^{3} \mathrm{H}\right]$ glucose is used as the isotope $(43,44)$. The accuracy of the tracer determined glucose production rates (total glucose production) in the present set of experiments is supported by the finding that they were very similar to those calculated from data obtained with the A-V difference technique (net hepatic glucose production). The difference between the rates calculated using the two methods could be accounted for by a small amount of extrahepatic (kidney) glucose production (46), by slight hepatic glucose uptake or by a combination of the two. It seems unlikely that hepatic glucose uptake would explain the small difference, however, since it has been reported that ${ }^{14} \mathrm{C}$ label does not accumulate in glycogen even after prolonged infusion of ${ }^{14} \mathrm{C}$ glucose into postabsorptive dogs (47). In the present study the basal rates of glucose production were similar in all experimental groups and were in accord with previously published data $(2,48,49)$. The rate of glucose utilization was also normal in each group and was equivalent to the rate of glucose production indicating that the animals were in a steady state for glucose.

Infusion of somatostatin resulted in a rapid and synchronous fall in the level of both insulin and glucagon. This finding is in agreement with earlier work carried out in vivo (21-24) and in vitro $(25,26)$. the portal:peripheral ratio of both hormones (1.6 for 


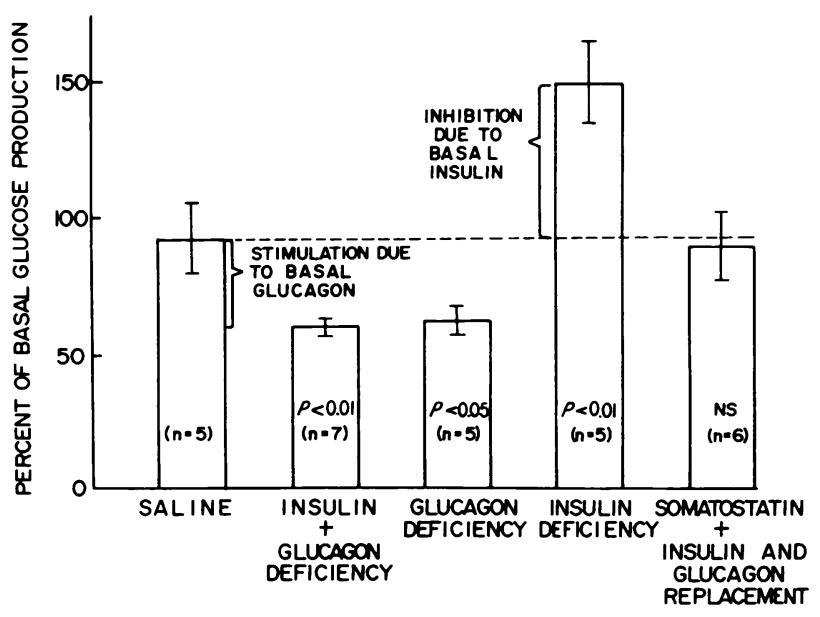

FIGURE 6 The effects of saline, somatostatin, somatostain + intraportal insulin, somatostatin + intraportal glucagon, and somatostatin + intraportal insulin and glucagon infusion in overnight fasted anesthetized dogs. Each bar represents the mean $\pm S E M$ percentage change in the rate of glucose production (isotopically determined) during the last $50 \mathrm{~min}$ of the treatment period. $P$ values were obtained (nonpaired $t$ test) by comparing the response in the treatment of group to the saline-infused group.

glucagon, 2.9 for insulin) fell to approximately 1.0 within $10 \mathrm{~min}$ of the start of somatostatin infusion suggesting that the secretion of both hormones was quickly inhibited. After $30 \mathrm{~min}$ of somatostatin infusion the IRI level was at or below the sensitivity of the assay $(5 \mu \mathrm{U} / \mathrm{ml})$, while the IRG level ranged from $20-60 \mathrm{pg} / \mathrm{ml}$. This residual glucagon immunoreactivity in all probability represents interfering factors in plasma which cross react with the $30 \mathrm{~K}$ antibody (50, 51). The conclusion that the drop in the IRG level represents for the most part a fall in "true" plasma glucagon is supported by the recent report that plasma taken from a somatostatin treated dog was devoid of "true" glucagon (mol wt 3,500) but still contained a normal amount of other materials which cross reacted with the $30 \mathrm{~K}$ antibody (52). The biological activity of this remnant material remains to be determined. If it is shown to have glycogenolytic or gluconeogenic activity, then the role of "true" glucagon in the regulation of glucose production is determined in this study may underestimate the overall role which all glucagon related material plays in control of glucose homeostasis. The fact remains, however, that infusion of somatostatin in the present studies, resulted in a rapid and pronounced deficiency (but not necessarily complete lack) of both insulin and glucagon.

After cessation of somatostatin infusion the concentrations of both insulin and glucagon rebounded quickly. The rapidity of the reversal attests to the short biological half life of somatostatin. The explanation for the somewhat larger rebound in glucagon may lie in the prevailing hypoglycemic stimulus which was present when the somatostatin-induced inhibition was withdrawn. It may have been accentuated by the possibility that hormone accumulated in the pancreas during the somatostatin infusion period.

The success of the replacement of pancreatic hormone secretion by intraportal insulin and glucagon infusion was demonstrated both by the level and the stability of the resulting hormone concentrations. Since glucagon and insulin were infused at their normal physiological site and at rates which maintained their plasma concentrations it was possible, by assuming their extraction had not changed, to estimate the secretion rate of each hormone. In the case of insulin, this was about $400 \mu \mathrm{U} / \mathrm{kg}$ per min, a value in agreement with earlier work $(53,54)$. Recently Fischer et al. (54), by using direct $\mathrm{A}-\mathrm{V}$ difference measurements in the postabsorptive dog, showed that the basal secretion

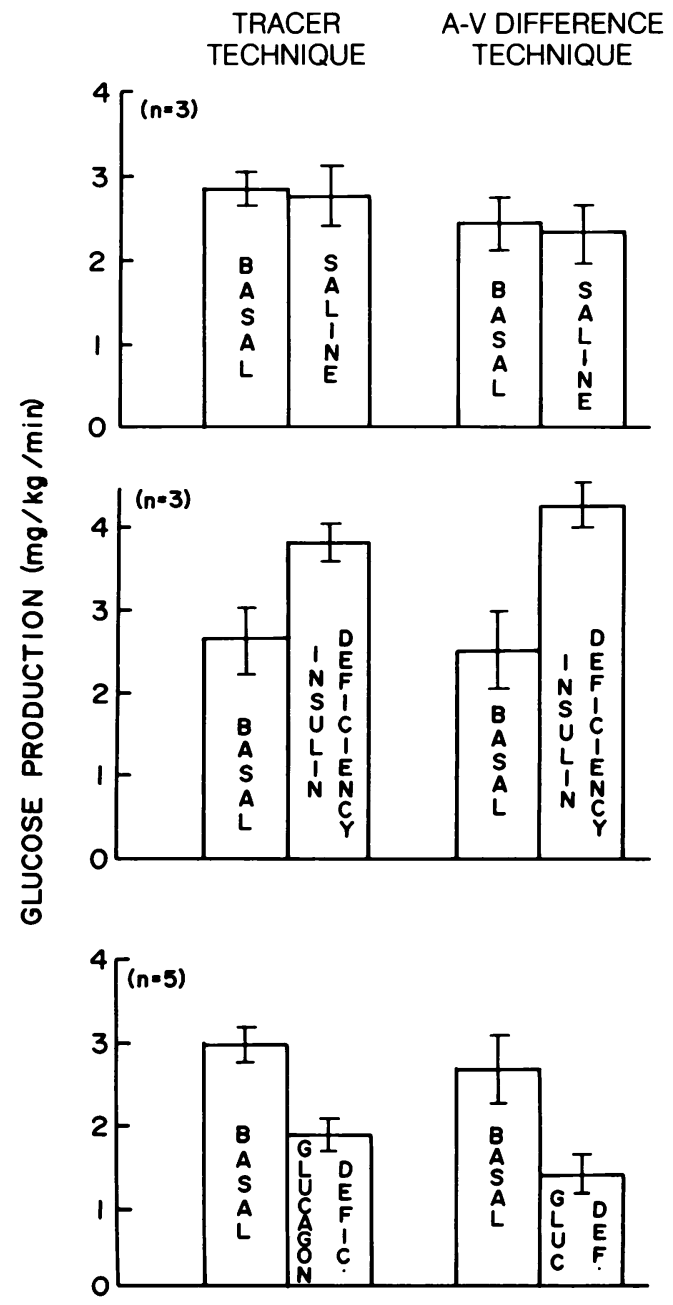

FIGURE 7 Glucose production measured by both tracer and A-V difference techniques in three different metabolic situations. Each bar represents the mean \pm SEM of the average production rate observed during the last $50 \mathrm{~min}$ of the treatment period. 
rate of insulin was $392 \mu \mathrm{U} / \mathrm{kg}$ per min. The basal secretion rate of glucagon, on the other hand, has not been as clearly assessed but it would appear from the present study that it is about $1 \mathrm{ng} / \mathrm{kg}$ per min in the postabsorptive state. This figure is similar to that suggested by Marliss et al. (55) who measured the A-V difference across the pancreas and by Iversen (56) who measured the rate of glucagon secretion by the perfused dog pancreas. After termination of the replacement infusion of either hormone the plasma concentration of that hormone remained relatively unaltered. This was presumably because the fall in the level of exogenously derived molecules was balanced by the increase in the concentration of endogenously derived hormone.

The potency of glucagon's effect on glycogenolysis and gluconeogenesis is well known $(12,32)$ but its physiological importance in the regulation of these processes is less clear. Mobilization of the hormone during arginine infusion, an analogy to protein ingestion, has recently been shown to be essential in preventing aminogenic hypoglycemia (48). In addition, it is now known that somatostatin-induced glucagon deficiency is associated with a drop in the glucose level despite coexistant insulin lack, suggesting that glucagon might be important in maintaining the basal rate of glucose production (57). The present study clearly demonstrates that such is the case and quantitates the importance of the hormone.

Hepatic glucose output fell markedly whenever glucagon secretion was inhibited, whether or not a fall in insulin accompanied the glucagon deficiency. It is now known that the presence or absence of insulin determines the duration of the depression of glucose production rather than the magnitude of the drop. ${ }^{3}$ Restoration of the glucagon level resulted in an immediate increase in the rate of glucose production. Furthermore, when basal glucagon levels were maintained by intraportal replacement of the hormone during somatostatin infusion the fall in glucose production failed to occur. A somatostatin-induced deficiency of both pancreatic hormones has previously been linked to a drop in glucose production in baboons (23), suggesting that the importance of basal glucagon in regulating glucose output is not limited to the dog. Nor is the importance of glucagon dependent upon anesthesia, since we observed a significant drop in glucose production $(28 \pm 4 \%, P<0.01, n=7)$ in conscious dogs given somatostatin (data not shown) as did others (58). It is worth noting that prolonged administration (i.e. for greater than $60 \mathrm{~min}$ ) of somatostatin alone does not result in a sustained decrease in glucose production (58). This finding is consistent with observations made in our laboratory in experiments in which the peptide

${ }^{3}$ Liljenquist, J. E., et al. Manuscript in preparation. was infused for $5 \mathrm{~h}$. The rebound in glucose production, however, was found to be dependent on insulin lack. ${ }^{4}$

The ability of insulin to inhibit glucose output by the liver both in vivo $(7,8)$ and in vitro $(6,9)$ is clearly established but its importance in basal amounts has not been defined. The present study clearly shows that specific inhibition of basal insulin secretion in the overnight fasted dog resulted in a significant increase in glucose production. This overproduction of glucose was totally abolished when the insulin level was allowed to return to normal and did not occur when the insulin level was maintained by means of an intraportal infusion during somatostatin treatment. The findings of the present study are in accord with those of Vranic and Wrenshall (59) who showed that cessation of intraportal insulin replacement in pancreatectomized dogs caused a $40 \%$ increase in glucose production. Although not known at the time, it is now apparent that such animals had normal glucagon levels $(19,48)$ and it seems likely that this increase in glucose production was glucagon induced. The inability of basal amounts of insulin to further inhibit the rate of glucose production during periods of acute glucagon deficiency is in line with in vitro data which suggest that effects of the hormone on unstimulated processes are difficult to detect $(4,12)$.

The present experiments show that somatostatin has no acute effects on glucose turnover other than those attributable to its modification of pancreatic hormone secretion. This is evident from the observation that the mean rates of glucose production and utilization were unchanged during somatostatin infusion when the insulin and glucagon levels were maintained by intraportal infusion. Such a conclusion is further supported by experiments, carried out with perfused rat hind quarters and isolated rat adipocytes in which somatostatin $(10-10,000 \mathrm{ng} / \mathrm{ml})$ had no effect on basal or insulin stimulated glucose uptake. ${ }^{5}$ Similar findings were reported in other skeletal muscle preparations $(60,61)$. It has been suggested that somatostatin $(70 \mathrm{ng} / \mathrm{ml})$ interferes with the ability of glucagon to stimulate glucose production by isolated hepatocytes (62); however, experiments with rat liver slices failed to support this conclusion (24). Studies from our laboratory in which isolated rat liver parenchymal cells were used have shown that somatostatin (10-1,000 $\mathrm{ng} / \mathrm{ml}$ ) had no effect on basal or glucagonstimulated glucose production and failed to modify the effect of glucagon (0.1-0.5 nM) on the acumulation of intracellular cyclic AMP or on the activation of cyclic AMP-dependent protein kinase. ${ }^{5}$

The data from the present experiments support the hypothesis that glucagon plays a significant role in

\footnotetext{
${ }^{4}$ Cherrington, A. D., et al. Manuscript in preparation.
}

${ }^{5}$ Cherrington, A. D., et al. Manuscript in preparation. 
regulating glucose production by the liver after an overnight fast. They also demonstrate the potency of insulin in restraining the effect of glucagon, thus suggesting that the fine regulation of glucose production is accomplished through the interaction of both pancreatic hormones. It is clear that isolated insulin deficiency is associated with a glucagon driven overproduction of glucose and a resulting hyperglycemia. The duration of the period of glucose overproduction after acute insulin deprivation remains to be determined. Even if it is short lived, however, it is possible that fluctuations in the glucagon level of a diabetic might result in bursts of glucose production or periods of impaired hepatic glucose uptake which although short lived would result in continued hyperglycemia, since the insulin necessary to clear the glucose from plasma would be unavailable.

\section{ACKNOWLEDGMENTS}

The authors would like to acknowledge the excellent technical assistance of Barbara Santoro, Phillip Williams, Edward Fryer, Leda Marshall, and Nancy Rogers. We are most grateful for the excellent secretarial skills of Lissa Hancock and Joyce Dawson.

This investigation was supported as follows: U. S. Public Health Service grant AM-18243, General Clinical Research Center grant RR95, and the Vanderbilt University DiabetesEndocrinology Center grant AM 17026.

\section{REFERENCES}

1. De Bodo, R. C., R. Steele, N. Altszuler, A. Dunn, and J. S. Bishop. 1963. On the hormonal regulation of carbohydrate metabolism: Studies with $\mathrm{C}^{14}$-glucose. Recent Prog. Horm. Res. 19: 445-488.

2. Cherrington, A. D., M. Vranic, P. Fono, and N. Kovacevic. 1972. Effect of glucagon on glucose turnover and plasma free fatty acids in depancreatized dogs maintained on matched insulin infusions. Can. J. Physiol. Pharmacol. 50: 946-954.

3. Liljenquist, J. E., J. D. Bomboy, S. B. Lewis, B. C. Sinclair-Smith, P. W. Felts, W. W. Lacy, O. B. Crofford, and G. W. Liddle. 1974. Effect of glucagon on net splanchnic cyclic AMP production in normal and diabetic man. J. Clin. Invest. 53: 198-204.

4. Park, C. R., and J. H. Exton. 1972. Glucagon and the metabolism of glucose. In Glucagon, Molecular Physiology, Clinical and Therapeutic Implications. P. J. Lefebvre and R. H. Unger, editors. Pergamon of Canada, Ltd., Don Mills, Ontario. 77-108.

5. Menahan, L. A., and O. Wieland. 1969. Interactions of glucagon and insulin on the metabolism of perfused livers from fasted rats. Eur. J. Biochem. 9: 55-62.

6. Jefferson, L. S., J. H. Exton, R. W. Butcher, E. W. Sutherland, and C. R. Park. 1968. Role of adenosine $3^{\prime}-5^{\prime}$ monophosphate in the effects of insulin and antiinsulin serum on liver metabolism. J. Biol. Chem. 243: 1031- 1038.

7. Madison, L. L., B. Combes, R. Adams, and W. Strickland. 1960. III. The physiological significance of the secretion of insulin into the portal circulation. III. Evidence for a direct immediate effect of insulin on the balance of glucose across the liver. J. Clin. Invest. 39: 507-522.
8. Steele, R., J. S. Bishop, A. Dunn, N. Altszuler, I. Rathgeb, and R. C. De Bodo. 1965. Inhibition by insulin of hepatic glucose production in the normal dog. Am.J. Physiol. 208: 301-306.

9. Mortimore, G. E., E. King, Jr., C. E. Mondon, and W. H. Glinsmann. 1967. Effects of insulin on net carbohydrate alterations in perfused rat liver. Am. J. Physiol. 212: $179-183$.

10. Starzl, T. E., W. A. Scanlan, F. H. Thornton, R. M. Wendel, B. Stearn, R. E. Lazarus, W. McAllister, and W. C. Shoemaker. 1965. Effect of insulin on glucose metabolism in the dog after portacaval transposition. Am. J. Physiol. 209: 221-226.

11. Wagle, S. R. 1975. Interrelationship of insulin and glucagon ratios on carbohydrate metabolism in isolated hepatocytes containing high glycogen. Biochem. Biophys. Res. Commun. 67: 1019-1027.

12. Exton, J. H., and C. R. Park. 1972. Interaction of insulin and glucagon in the control of liver metabolism. Handb. Physiol. Section 7. Endocrinology. 1: 437-455.

13. Mackrell, D. J., and J. E. Sokal. 1969. Antagonism between the effects of insulin and glucagon on the isolated liver. Diabetes. 18: 724-732.

14. Parrilla, R., M. N. Goodman, and C. J. Toews. 1974. Effect of glucagon:insulin ratios on hepatic metabolism. Diabetes. 23: 725-731.

15. Unger, R. H. 1976. Diabetes and the alpha cell. Diabetes. 25: $136-151$.

16. Sasagawa, T., S. Kobayaski, and T. Fujita. 1974. Electron microscope studies on the endocrine cells of the human gut and pancreas. In Gastro-Entero-Pancreatic Endocrine System. A Cell Biological Approach. T. Fujita, editor. Tokyo, Igaku Shoin Ltd., Tokyo. 17-38.

17. Sasaki, H., B. Rubalcava, D. Baetens, E. Blazquez, C. B. Srikant, L. Orci, and R. H. Unger. 1975. Identification of glucagon in the gastrointestinal tract. J. Clin. Invest. 56: $135-145$.

18. Mashiter, K., P. E. Harding, M. Chou, G. D. Mashiter, J. Stout, D. Diamond, and J. B. Field. 1975. Persistent pancreatic glucagon but not insulin response to arginine in pancreatectomized dogs. Endocrinology. 96: 678-693.

19. Vranic, M., S. Pek, and R. Kawamori. 1974. Increased "glucagon immunoreactivity" in the plasma of totally depancreatized dogs. Diabetes. 23: 905-912.

20. Matsuyama, T., and P. P. Foa. 1974. Effects of pancreatectomy and of enteral administration of glucose on plasma insulin, total and pancreatic glucagon. Proc. Soc. Exp. Biol. Med. 147: 97-102.

21. Efendić, S., A. Claro, and R. Luft. 1976. Studies on the mechanism of somatostatin action on insulin release. III. Effect of somatostatin on arginine induced release of insulin and glucagon in man and perfused rat pancreas. Acta Endocrinol. 81: 753-761.

22. Leblanc, H., and S. C. Yen. 1975. Comparison of cyclic and linear forms of somatostatin in the inhibition of growth hormone, insulin and glucagon secretion.J. Clin. Endocrinol. Metab. 40: 906-908.

23. Koerker, D. J., W. Ruch, E. Chideckel, J. Palmer, C. J. Goodner, J. Ensinck, and C. C. Gale. 1974. Somatostatin: hypothalamic inhibitor of the endocrine pancreas. Science (Wash. D. C.). 184: 482-484.

24. Chideckel, E., J. Palmer, D. J. Koerker, J. Ensinck, M. B. Davidson, and C. J. Goodner. 1975. Somatostatin blockade of acute and chronic stimuli of the endocrine pancreas and consequences of this blockade on glucose homeostasis. J. Clin. Invest. 55: 754-762.

25. Curry, D. L., and L. L. Bennett. 1974. Reversal of 
somatostatin inhibition of insulin secretion by calcium. Biochem. Biophys. Res. Commun. 60: 1015-1019.

26. Iversen, J. 1974. Inhibition of pancreatic glucagon release by somatostatin in vitro. Scand. J. Clin. Lab. Invest. 33: 125-129.

27. Sakurai, H., R. E. Dobbs, and R. H. Unger. 1975. The role of glucagon in the pathogenesis of the endogenous hyperglycemia of diabetes mellitus. Metab. Clin. Exp. 24: 1287-1297.

28. Curry, D. L., and L. Bennett. 1976. Does somatostatin inhibition of insulin secretion involve two mechanisms of action? Proc. Natl. Acad. Sci. U.S.A. 73: 248-251.

29. Fujimoto, W. Y., and J. W. Ensinck. 1976. Somatostain inhibition of insulin and glucagon secretion in rat islet culture; reversal by ionophore A23187. Endocrinology. 98: 259-262.

30. Efendic, S., V. Grill, and R. Luft. 1975. Inhibition by somatostatin of glucose induced $3^{\prime}: 5^{\prime}$-monophosphate (cyclic AMP) accumulation and insulin release in isolated pancreatic islets of the rat. F. E. B. S. (Fed. Eur. Biochem. Soc.) Lett. 55: 131-133.

31. Kaneko, T., H. Oka, M. Munemura, S. Susuki, H. Yasuda, and T. Oda. 1974. Stimulation of guanosine 3',5'-cyclic monophosphate accumulation in rat anterior pituitary gland in vitro by synthetic somatostatin. Biochem. Biophys. Res. Commun. 61: 53-57.

32. Chiasson, J. L., J. E. Liljenquist, B. C. Sinclair-Smith, and W. W. Lacy. 1975. Gluconeogenesis from alalnine in normal postabsorptive man. Intrahepatic stimulatory effect of glucagon. Diabetes 24: 574-584.

33. Aguilar-Parada, E., A. M. Eisentraut, and R. H. Unger. 1969. Pancreatic glucagon secretion in normal and diabetic subjects. Am. J. Med. Sci. 257: 415-419.

34. Wide, L., and J. Porath. 1966. Radioimmunoassay of proteins with the use of Sephadex-coupled antibodies. Biochim. Biophys. Acta. 130: 257-260.

35. Leevy, C. M., C. L. Mendenhall, W. Lesko, and M. M. Howard. 1962. Estimation of hepatic blood flow with indocyanine green. J. Clin. Invest. 41: 1169-1179.

36. Wall, J. S., R. Steele, R. C. De Bodo, and N. Altszuler. 1957. Effect of insulin on utilization and production of circulating glucose. Am. J. Physiol. 189: 43-50.

37. Cowan, J. S., and G. Hetenyi, Jr. 1971. Glucoregulatory responses in normal and diabetic dogs recorded by a new tracer method. Metab. Clin. Exp. 20: 360-372.

38. Cherrington, A. D., and M. Vranic. 1973. Effect of arginine on glucose turnover and plasma free fatty acids in normal dogs. Diabetes 22: 537-543.

39. Radziuk, J., K. H. Norwich, and M. Vranic. 1974. Measurement and validation of nonsteady turnover rates with applications to the insulin and glucose systems. Fed. Proc. 33: 1855-1864.

40. Radziuk, J., M. Vranic, and K. H. Norwich. 1974. Experimental validation of tracer-determined nonsteady glucose turnover rates and a functional relationship between glucose clearance and insulin levels. Fed. Proc. 33: 276. (Abstr.)

41. Greenway, C. V., and R. D. Stark. 1971. Hepatic vascular bed. Physiol. Rev. 51: 23-65.

42. Snedecor, G. W., and W. G. Cochran. 1967. Statistical Methods. Iowa State University Press, Ames, Iowa. 6th edition. $593 \mathrm{pp}$.

43. Altszuler, N., A. Barkai, C. Bjerknes, B. Gottlieb, and R. Steele. 1975. Glucose turnover values in the dog obtained with various species of labeled glucose. Am. J. Physiol. 229: 1662-1667.

44. Dunn, A., K. Bever, M. Chenoweth and J. Katz. 1975. The estimation of glucose recycling in vivo using ${ }^{3} \mathrm{H}$ and ${ }^{14} \mathrm{C}$ labeled glucose. Fed. Proc. 34: 465. (Abstr.)
45. Katz, J., and A. Dunn. 1967. Glucose-2-T as a tracer for glucose metabolism. Biochemistry. 6: 1-5.

46. Krebs, H. 1963. Gluconeogenesis. Proc. R. Soc. Lond. B Biol. Sci. 159: 545-564.

47. Bishop, J. S., R. Steele, N. Altszuler, A. Dunn, C. Bjerknes, and R. C. De Bodo. 1965. Effects of insulin on liver glycogen synthesis and breakdown in the dog. Am. J. Physiol. 208: 307-316.

48. Cherrington, A. D., R. Kawamori, S. Pek, and M. Vranic. 1974. Arginine infusion in dogs. Model for the roles of insulin and glucagon in regulating glucose turnover and free fatty acid levels. Diabetes 23: 805-815.

49. Ishiwata, K., G. Hetenyi, Jr., and M. Vranic. 1969. Effect of d-glucose or d-ribose on the turnover of glucose in pancratectomized dogs maintained on a matched intraportal infusion of insulin. Diabetes 18: 820-827.

50. Valverde, I., M. L. Villanueva, I. Lozano, and J. Marco. 1974. Presence of glucagon immunoreactivity in the globulin fraction of human plasma ("Big Plasma Glucagon”). J. Clin. Endocrinol. Metab. 39: 1090-1098.

51. Weir, G. C., S. D. Knowlton, and D. B. Martin. 1975. High molecular weight glucagon-like immunoreactivity in plasma. J. Clin. Endocrinol. Metab. 40: 296-302.

52. Valverde, I., R. Dobbs, and R. H. Unger. 1975. Heterogeneity of plasma-glucagon immunoreactivity in normal, depancreatized, and alloxan-diabetic dogs. Metab. Clin. Exp. 24: 1021-1028.

53. Kanazawa, Y., T. Kuzuya, and T. Ide. 1968. Insulin output via the pancreatic vein and plasma insulin response to glucose in dogs. Am. J. Physiol. 215: 620-626.

54. Fischer, U., H. Hommel, H-D. Gottschling, P. Heinke, and E. Jutzi. 1975. Estimation of pancreatic IRI output rate and its relation to glucose tolerance in normal anesthetized dogs. Diabetologia. 11: 291-299.

55. Marliss, E. B., L. Girardier, J. Seydoux, C. B. Wollheim, Y. Kanazawa, L. Orci, A. E. Renold, and D. Porte, Jr. 1973. Glucagon release induced by pancreatic nerve stimulation in the dog. J. Clin. Invest. 52: 1246-1259.

56. Iversen, J. 1971. Secretion of glucagon from the isolated, perfused canine pancreas. J. Clin. Invest. 50: 2123-2136.

57. Alford, F. P., S. R. Bloom, J. D. N. Nabarro, R. Hall, G. M. Besser, D. H. Coy, A. J. Kastin, and A. V. Schally. 1974. Glucagon control of fasting glucose in man. Lancet II: 974-977.

58. Altszuler, N., B. Gottlieb, and J. Hampshire. 1976. Interaction of somatostatin, glucagon, and insulin on hepatic glucose output in the normal dog. Diabetes 25: $116-121$.

59. Vranic, M., and G. A. Wrenshall. 1968. Matched rates of insulin infusion and secretion and concurrent tracerdetermined rates of glucose appearance and disappearance in fasting dogs. Can. J. Physiol. Pharmacol. 46: $383-390$.

60. Haas, R., E. Clausen, C. Woods, M. Lorenzi, D. Bier, S. Hane, and J. E. Gerich. 1975. Effect of somatostatin, insulin, and glucagon on glucose uptake and alanine release by the isolated perfused rat hind-limb. Clin. Res. 23: 110A. (Abstr.)

61. Gerich, J. E., M. Lorenzi, S. Hane, G. Gustafson, R. Guillemin, and P. H. Forsham. 1975. Evidence for a physiological role of pancreatic glucagon in human glucose homeostasis: studies with somatostatin. Metab. Clin. Exp. 24: 175-182.

62. Oliver, J. R., and S. R. Wagle, 1975. Studies on the inhibition of insulin release, glycogenolysis and gluconeogenesis by somatostatin in rat islets of Langerhans and isolated hepatocytes. Biochem. Biophys. Res. Commun. 62: 777 . 